\title{
The Influences of Thickness on the Optical and Electrical Properties of Dual-Ion-Beam Sputtering-Deposited Molybdenum-Doped Zinc Oxide Layer
}

\author{
Chin-Chiuan Kuo, ${ }^{1}$ Chi-Chang Liu, ${ }^{1}$ Shao-Chih He, ${ }^{2}$ Jing-Tang Chang, ${ }^{2}$ and Ju-Liang He ${ }^{2}$ \\ ${ }^{1}$ Department of Mechanical Engineering, Chien Kuo Technology University, Changhua 50058, Taiwan \\ ${ }^{2}$ Department of Materials Science and Engineering, Feng Chia University, Taichung 40724, Taiwan \\ Correspondence should be addressed to Chin-Chiuan Kuo, cckuo@ctu.edu.tw
}

Received 8 June 2011; Revised 25 August 2011; Accepted 26 August 2011

Academic Editor: Sheng-Rui Jian

Copyright (C) 2011 Chin-Chiuan Kuo et al. This is an open access article distributed under the Creative Commons Attribution License, which permits unrestricted use, distribution, and reproduction in any medium, provided the original work is properly cited.

\begin{abstract}
The thickness of transparent conductive oxide (TCO) layer significantly affects not only the optical and electrical properties, but also its mechanical durability. To evaluate these influences on the molybdenum-doped zinc oxide layer deposited on a flexible polyethersulfone (PES) substrate by using a dual-ion-beam sputtering system, films with various thicknesses were prepared at a same condition and their optical and electrical performances have been compared. The results show that all the deposited films present a crystalline wurtzite structure, but the preferred orientation changes from (002) to (100) with increasing the film thickness. Thicker layer contains a relative higher carrier concentration, but the consequently accumulated higher internal stress might crack the film and retard the carrier mobility. The competition of these two opposite trends for carrier concentration and carrier mobility results in that the electrical resistivity of molybdenum-doped zinc oxide first decreases with the thickness but suddenly rises when a critical thickness is reached.
\end{abstract}

\section{Introduction}

Transparent conductive oxides (TCOs), such as indium tin oxide (ITO), have been extensively applied for electrodes in flat displayer, panel, sensor, organic light emitting diode, solar cell, and so forth [1-4]. To moderate the impact of indium shortage, various zinc oxides, which have advantages on low cost, environmentally friendly, easy to etch, and nonreactive with hydrogen plasma [5], have been developed as new alternatives. Doping elements of group II and IV is a known method to increase the carrier concentration for improving the conductivity of zinc oxide. Among these doped zinc oxides, the molybdenum-doped zinc oxide (hereafter abbreviated as MZO), in which every substitution of $\mathrm{Mo}^{6+}$ for $\mathrm{Zn}^{2+}$ site in the wurtzite cell can induce 4 extra carriers, promotes it to be the most potential n-type transparent semiconductor over all alternatives.

To fulfill the demands of flexible and portable electronic, polymeric materials are the currently most chosen substrates of TCOs for such applications. However, the low thermal tolerance of commonlyused polymers restricts the options for the process temperature of other integrated materials. Dual-ion-beam sputtering deposition (DIBSD) [6] is one of the low-temperature deposition techniques. DIBSD is to use an argon ion beam generated from the ion source to sputter atoms of the target surface. The high kinetic energy transferred from the incident ions to the sputtered particles provides them the required activation energy for the nucleation and synthesis reactions during the film growth. Furthermore, one additional assistant ion beam irradiates the deposit surface simultaneously, which provides an additional energy for adatoms migration to arrange a dense crystalline structure. Both kinds of ion beam enable the deposition of crystalline MZO films onto the polyethersulfone (PES) substrates at low processing temperature.

It is well known that the electrical conductivity usually increases and the optical transparency usually decreases with the thickness of TCO layer [7]. To trade off between 
TABLE 1: Deposition parameters for $\mathrm{SiO}_{2}$ buffer layer.

\begin{tabular}{lc}
\hline Parameter & Composition, setting \\
\hline Target material & $4 \mathrm{~N} \mathrm{SiO}_{2}$ \\
Working pressure $(\mathrm{Pa})$ & 0.67 \\
Substrate temperature $\left({ }^{\circ} \mathrm{C}\right)$ & 130 \\
Film growth rate $(\mathrm{nm} / \mathrm{s})$ & 0.05 \\
Film thickness $(\mathrm{nm})$ & 70 \\
\hline
\end{tabular}

these two requirements is an important issue for specific applications. In this work, the influences of the thickness on the crystallinity, surface morphology, optical transparency, and resistivity of deposited MZO have been studied.

\section{Experimental Procedures}

The PES substrates were $2 \mathrm{~cm} \times 2 \mathrm{~cm}$ squares with a $135 \mu \mathrm{m}$ thickness. The source MZO target within a size of $10.2 \mathrm{~mm}$ in diameter and $3.0 \mathrm{~mm}$ thick which composed of $97 \mathrm{wt} . \%$ $\mathrm{ZnO}$ and $3 \mathrm{wt} . \% \mathrm{MoO}_{3}$ with a $4 \mathrm{~N}$ purity is made by LTS Chemical Inc. The deposition of MZO was carried out in a customized DIBSD system (JUNSUN TECH IBS-600). In the deposition chamber, one Kaufman-type convergent ion source (Veeco 05 DC-PKG ASSY) with a plasma bridge neutralizer $(\mathrm{PBN})$ is for sputtering the $\mathrm{MZO}$ target. This PBN contains a hot filament in a discharge chamber supplied with an argon gas, and the electrons are extracted from the plasma generated in the discharge chamber. One endHall-type divergent assistant ion source (KRI EH-200) with a hollow cathode electron source neutralizer is used as an assistant ion beam source for bombarding the specimen. The deposit thickness is controlled by applying quartz, the crystal deposition controller (ULVAC Inc., CRTM-6000).

Prior to the film deposition, substrates were ion bombarded by using the assistant ion source for $10 \mathrm{~min}$ to decontaminate and to flat the PES surface. One thin $\mathrm{SiO}_{2}$ buffer layer was first coated without applying assistant ion beam for isolating the permeation of water or polymer vapor from substrate into following MZO film. This buffer layer also could moderate the compressive stress in MZO and consequent rumpling due to the substrate shrinkage. The sequent MZO deposition was carried out under a dual-ion-beam mode with constant working pressure of $0.67 \mathrm{~Pa}$, substrate temperature of $130{ }^{\circ} \mathrm{C}$, and deposition rate of $0.05 \mathrm{~nm} / \mathrm{s}$. Based on previous research results [8], the discharge voltage and current of assistant ion source were constantly set at $100 \mathrm{~V}$ and 1.4 A. Each MZO film of different thickness, 80, $100,120,140,160,180$, and 200, was deposited onto the substrate sheet individually. The deposition conditions of $\mathrm{SiO}_{2}$ buffer layer and $\mathrm{MZO}$ films are, respectively, listed in Tables 1 and 2 .

The film structural characterization was done by using a Bruker D8-SSS multipurpose thin-film X-ray diffractometer at a glancing incident angle of $1.8^{\circ}$ with a scan rate of $3^{\circ} / \mathrm{min}$ from $2 \theta 20^{\circ}$ to $60^{\circ}$. A HITACHI S-4800 field-emission scanning electron microscope was used to observe the surface and cross-sectional morphology of films. The electrical resistivity
TABle 2: Conditions and ion beam settings for MZO deposition.

\begin{tabular}{lc}
\hline Parameter & Composition, setting \\
\hline Target material & $4 \mathrm{~N} \mathrm{ZnO} / \mathrm{MoO}_{3}(97 / 3 \mathrm{wt} \%)$ \\
Working pressure $(\mathrm{Pa})$ & 0.67 \\
Substrate temperature $\left({ }^{\circ} \mathrm{C}\right)$ & 130 \\
Film growth rate $(\mathrm{nm} / \mathrm{s})$ & 0.05 \\
Assistant ion beam & 100 \\
$\quad$ Discharge voltage $(\mathrm{V})$ & 1.4 \\
$\quad$ Discharge current $(\mathrm{A})$ & $80,100,120,140,160,180,200$ \\
\hline Film thickness $(\mathrm{nm})$ &
\end{tabular}

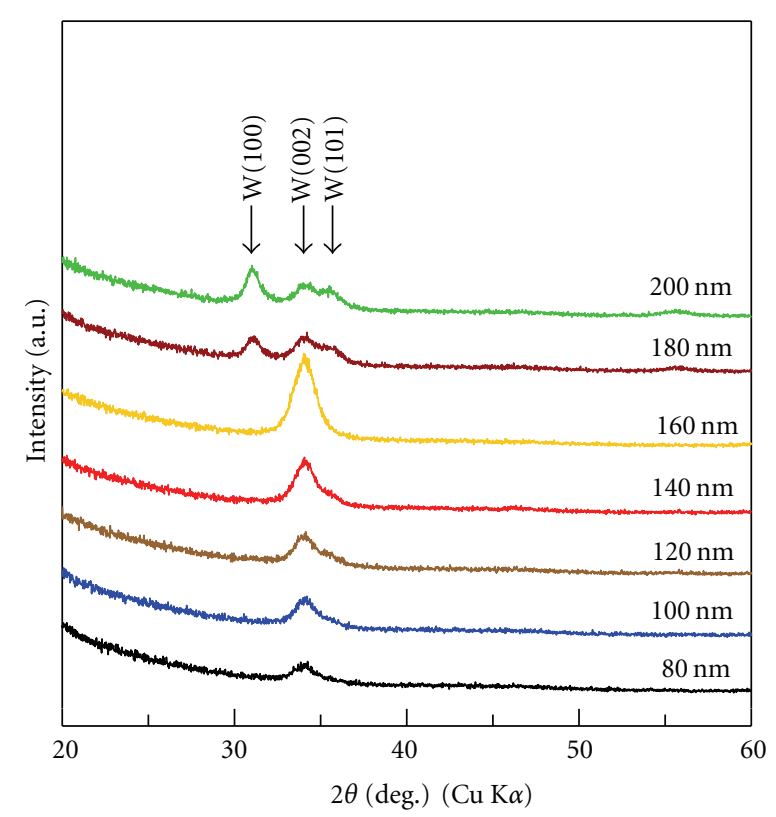

FIgure 1: The X-ray diffraction patterns of deposited MZO films with different thickness.

of $\mathrm{MZO}$ was measured by utilizing the four-point probe (Quatek QT-50). The carrier concentration and mobility of $\mathrm{MZO}$ were determined by the Hall effect measurement (Ecopia HMS-3000). The optical band gap of MZO is estimated from the absorption spectra of deposited specimens measured by a Shimadzu UV-1700 UV-visible spectrophotometer. The figure of merit (FOM), $T^{10} / R_{s}$ by Haacke [9] at different wavelengths, for each specimen is calculated from measured optical transmittance, $T$, and sheet resistance, $R_{s}$.

\section{Results and Discussion}

The variation of X-ray diffraction patterns of $\mathrm{MZO}$ films with the thickness can be seen in Figure 1. For the MZO layers thinner than $160 \mathrm{~nm}$, there are only one significant diffraction peak of hexagonal wurtzite-phase $\mathrm{ZnO}$ around $34.17^{\circ}$, labeled as $\mathrm{W}(002)$. The peak intensity also strengthens with the film thickness. This implies the higher crystallinity or a preferred crystal orientation of thicker MZO 

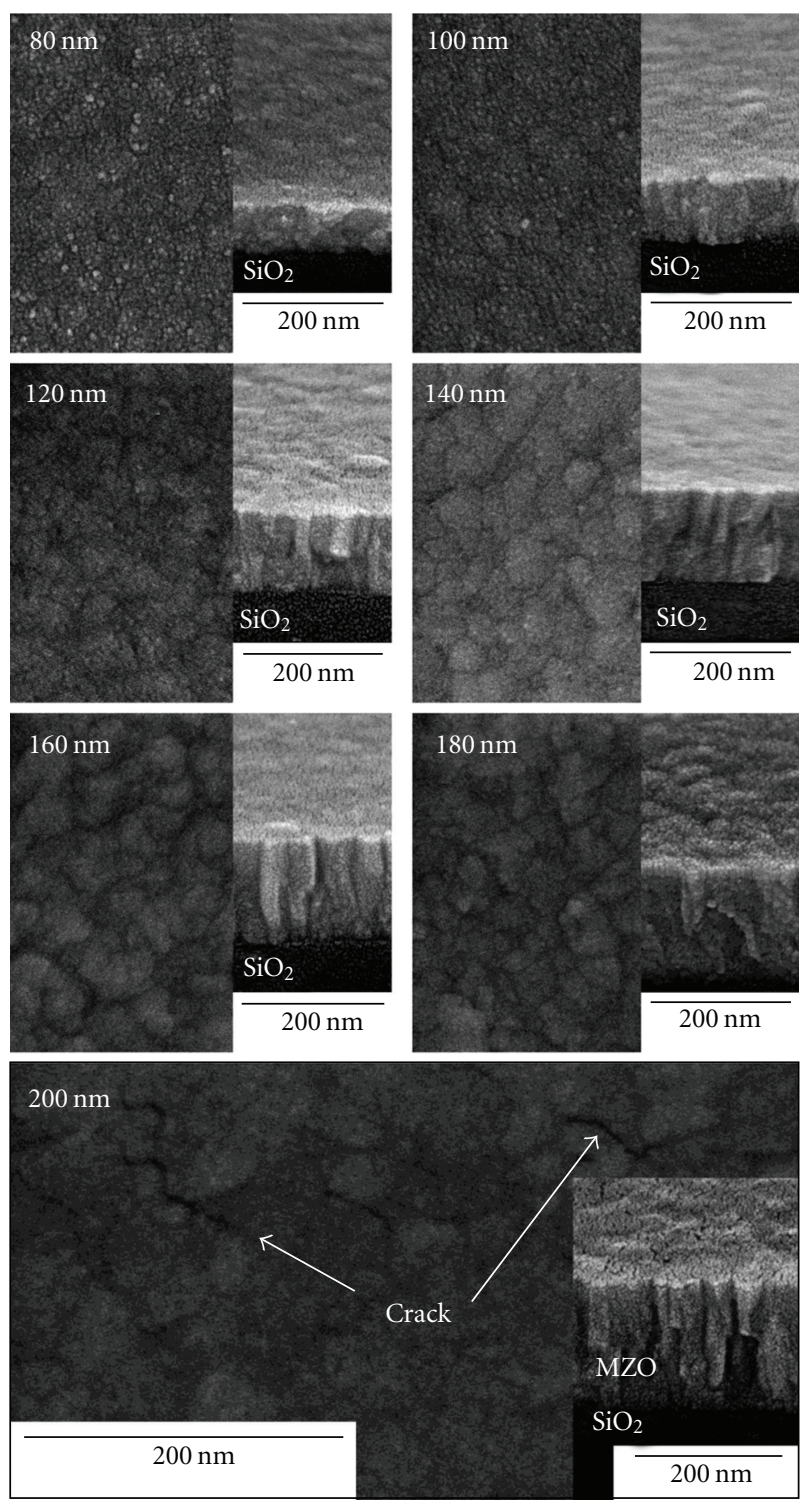

FIgURE 2: The surface and cross-sectional morphologies of deposited MZO films with different thickness. The arrows indicate cracks along the projection boundary.

layers. However, when the MZO layer is thicker than $160 \mathrm{~nm}$, the intensity of (002) suddenly drops, and the other two orientations, (100) and (101), appear at $31.08^{\circ}$ and $36.06^{\circ}$. These orientation changes might be due to the accumulated internal stress in MZO layer. The internal stress might cause the preferred (002) orientation or further refine the grain. Similar phenomenon has been found in different processes. Xiu et al. found that the preferred orientation of MZOfilm RF sputtering deposited on glass changes with the film thickness. They also noticed the appearance of black caves and protrusion on the film surface with increasing film thickness [10]. Similar trends have also been reported in our previous work of Mo-doped $\operatorname{In}_{2} \mathrm{O}_{3}$ films deposited on PES by using ion-beam-assisted evaporation [11] where the thickness is below $170 \mathrm{~nm}$.

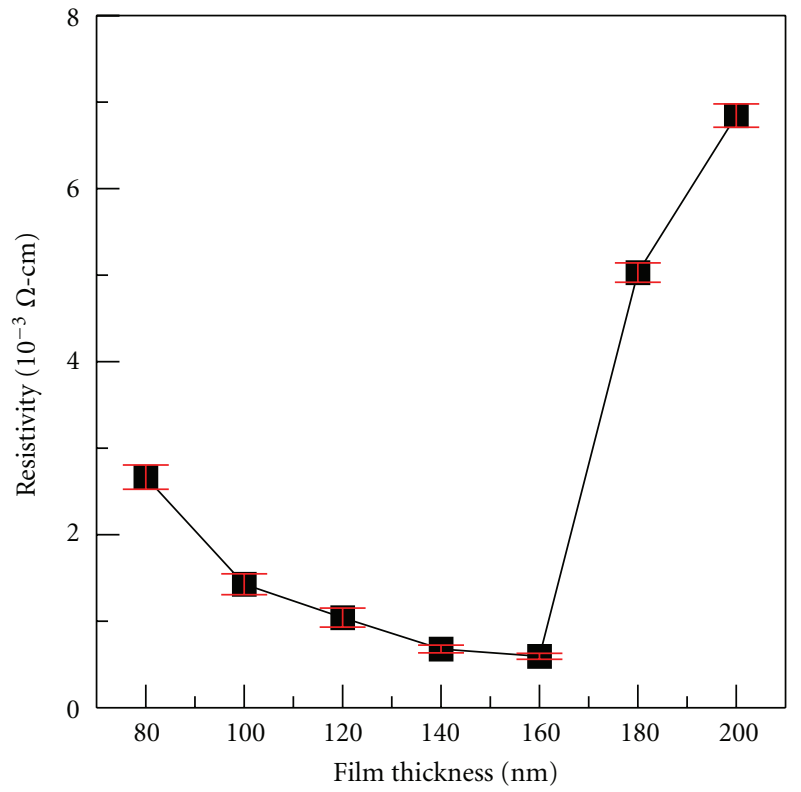

FIGURE 3: Dependence of the electrical resistivity on the thickness of deposited MZO films.

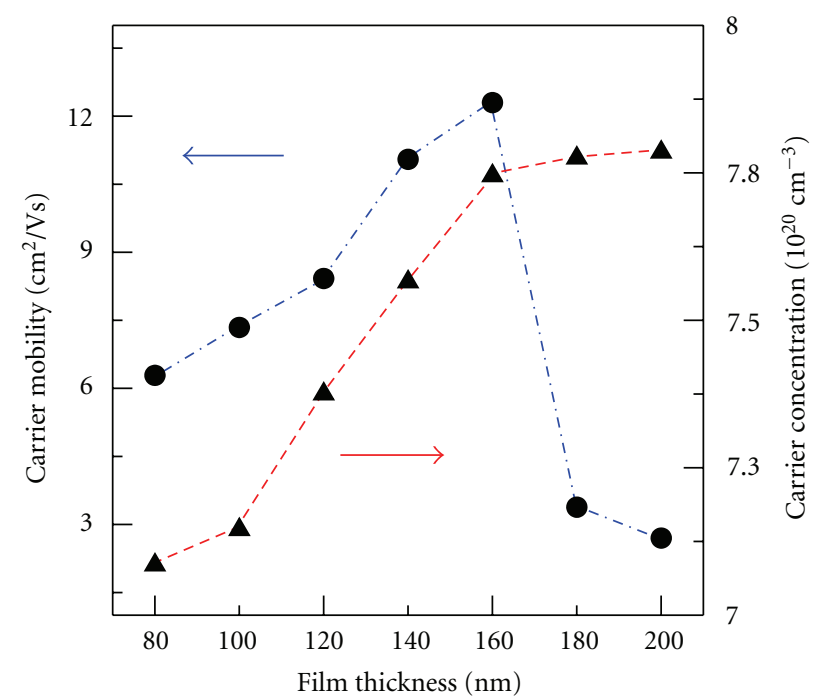

FIGURE 4: Dependence of the carrier mobility and concentration on the thickness of deposited MZO films.

The surface and cross-sectional morphologies of MZO films with different thickness are shown in Figure 2. The brighter layers are MZO. The dark layers with grey dots beneath the MZO are $\mathrm{SiO}_{2}$ buffer layer. The $80 \mathrm{~nm}$ thick film exhibits a flatter and fine granular featured surface. It also presents a relatively epitaxial and noncolumnar feature, which indicates it still remains a nucleation stage. Above $100 \mathrm{~nm}$ thick, the obvious columnar feature and surface projections (also called domain) can be found in crosssectional and surface images, respectively. The size and width of projections enlarge with the film thickness, reaches a maximum on $160 \mathrm{~nm}$ thick film, then it reduces. The trend of 


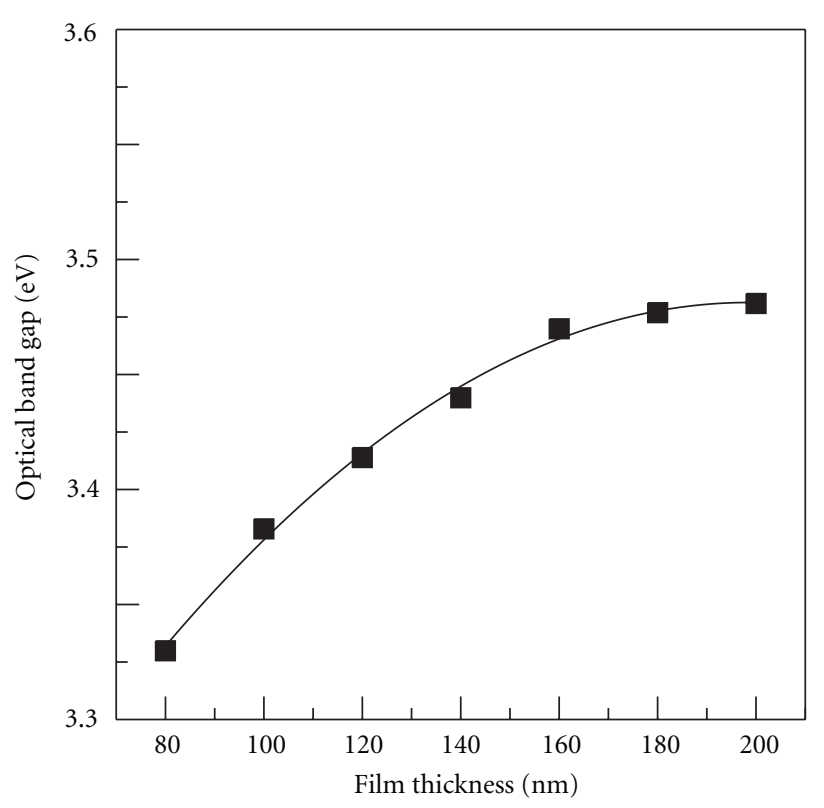

FIGURE 5: Estimated energy gap of MZO films with different thickness.

projection size corresponds to the diffraction peak intensity in Figure 1 XRD patterns. However, when the film thickness is over $180 \mathrm{~nm}$, there are not only the smaller projections but also cracks along projection boundary on the thick film. These cracks might be induced by the accumulated internal stress in stacking defects due to difference of thermal expansion coefficients between PES substrate and MZO layer [12]. Same situation has also occurred in Fortunato's work and increased the electrical resistivity of deposits [13].

The measured electrical resistivity of each deposited MZO film shown in Figure 3 also agrees with this. The electrical resistivity of MZO initially increases with film thickness as the typical trend for TCOs on glass substrate $[12,14]$, until it reaches a minimum, $5.95 \times 10^{-4} \Omega-\mathrm{cm}$, on the $160 \mathrm{~nm}$ thick MZO, then suddenly rises.

To further investigate the causes of different electrical resistivity, the carrier concentration and mobility in deposited MZO were determined and shown in Figure 4. The carrier concentration increases with the film thickness but subsequently becomes constant when the film thickness is over $160 \mathrm{~nm}$. For the films below $160 \mathrm{~nm}$, the increase of carrier concentration might be attributed to increased fraction of crystalline phase. The $80 \mathrm{~nm}$ thick film exhibits a more disordered structure which contains lesser carriers [15]. There are also more stacking defects in thinner films. These defects trap the carriers and lower down the concentration of free carriers [16, 17]. For films over $180 \mathrm{~nm}$ due to the defects induced by the crystalline orientation, change offsets the positive effect from higher crystallinity $[10,13]$. Differently, the carrier mobility initially increases with the film thickness but suddenly reduces when the film thickness is over $160 \mathrm{~nm}$. This explains the above correlation between overall electrical resistivity and film thickness. The thinner film with disordered structure exhibits a relatively smaller

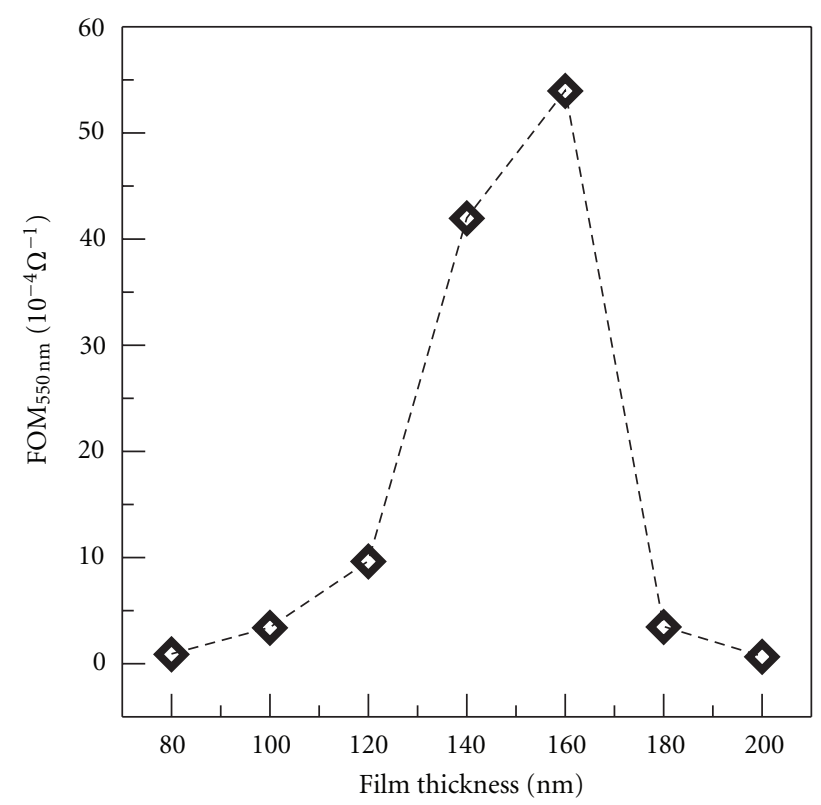

FIGURE 6: Calculated figure of merit value of $550 \mathrm{~nm}$ for MZO films with different thickness.

projection size and more boundaries. Those boundaries and defects scatter the carriers and retard the carrier mobility. The sharp decrease of carrier mobility when the thickness is over $160 \mathrm{~nm}$ can be attributed to the structural discontinuity or cracks. Similar phenomena have been reported in indium tin oxide film deposition $[18,19]$.

The optical band gap values of MZO films estimated from absorption spectra of different MZO-coated specimens are shown in Figure 5. The optical band gap slightly increases with the film thickness from 3.33 to $3.481 \mathrm{eV}$. It presents the same trend as the carrier concentration results in Figure 4. It indicates that the optical band gap of MZO films is dominated by the carrier concentration $[20,21]$ due to the Burstein-Moss effect. The overall performance of these MZO transparent conductive layers with different thickness can be compared by the figure of merit values as shown in Figure 6. Since the average transmittance of visible region for specimens of all thickness is approximately $80 \%$, the FOM value is dominated by the electrical performances of MZO layer. Due to the lowest resistivity, the $160 \mathrm{~nm}$ thick MZO film has a maximum figure of merit value, $5.49 \times 10^{-3} \Omega^{-1}$.

According to the above results, an optimum film thickness for MZO film deposited by dual-ion-beam sputtering on $\mathrm{SiO}_{2}$-precoated polyethersulfone in this study is achieved. The $160 \mathrm{~nm}$ thick MZO presents a lowest resistivity of $5.95 \times$ $10^{-4} \Omega-\mathrm{cm}$ and highest figure of merit value, which fulfills all the demands for the transparent electrode applications.

\section{Conclusions}

In this study, molybdenum-doped zinc oxide layers with different thickness were, respectively, deposited onto flexible polyethersulfone substrates by using a dual-ion-beam sputtering system within the same deposition atmosphere 
and constant sputter ion-beam settings. The influences of film thickness on their optical and electrical performances have been investigated. Below the critical thickness, the accumulated internal stress with thickness promotes a preferred (002) orientation of crystal structure and enhances the film conductivity. However, when the thickness is over the critical value, the excess internal stress cause structural discontinuity by the bifurcated orientation, and it might also crack the film; these both restrict the carrier mobility and reduce the conductivity.

\section{References}

[1] M. Higgins, S. Uekusa, P. Nakano, and K. Yokogawa, "Postdeposition annealing influence on sputtered indium tin oxide film characteristics," Japanese Journal of Applied Physics, Part 1, vol. 33, no. 1, pp. 302-306, 1994.

[2] A. Subrahmanyam, C. Suresh Kumar, and K. Muthu Karuppasamy, "A note on fast protonic solid state electrochromic device: NiOx/Ta2O5/WO3-x," Solar Energy Materials and Solar Cells, vol. 91, no. 1, pp. 62-66, 2007.

[3] X. Jiang, F. L. Wong, M. K. Fung, and S. T. Lee, "Aluminumdoped zinc oxide films as transparent conductive electrode for organic light-emitting devices," Applied Physics Letters, vol. 83, no. 9, pp. 1875-1877, 2003.

[4] A. Gupta and A. D. Compaan, "All-sputtered 14\% CdS/CdTe thin-film solar cell with $\mathrm{ZnO}$ : al transparent conducting oxide," Applied Physics Letters, vol. 85, no. 4, pp. 684-686, 2004.

[5] S. Kim, W. Lee, and C. Lee, "Influence of $\mathrm{ZnO}$ buffer layer thickness on electrical and optical properties of GZO thin films deposited on polymer substrate," Materials Science and Technology, vol. 23, 303, 2007.

[6] Y. Suzuki, T. Yotsuya, M. Yoshitake, K. Takiguchi, and S. Ogawa, "Modification of $\mathrm{ZnO}$ crystal orientation in dual ion beam sputtering deposition," Nucl. Instrum. Methods Phys. Res. Sect. B-Beam Interact. Mater. Atoms, vol. 39, 732, 1989.

[7] C. Liu, T. Matsutani, T. Asanuma et al., "Room-temperature growth of crystalline indium tin oxide films on glass using low-energy oxygen-ion-beam assisted deposition," Journal of Applied Physics, vol. 93, no. 4, pp. 2262-2266, 2003.

[8] C. C. Kuo, C. C. Liu, S. C. He, J. T. Chang, and J. L. He, "Influence of assistant ion beam on the opto-electrical properties of molybdenum doped zinc oxide films deposited on polyethersulfone via dual ion beam sputtering," Vacuum, vol. 85, 961, 2011.

[9] G. Haacke, "New figure of merit for transparent conductors," Journal of Applied Physics, vol. 47, no. 9, pp. 4086-4089, 1976.

[10] X. Xiu, Z. Pang, M. Lv, Y. Dai, L. Ye, and S. Han, "Transparent conducting molybdenum-doped zinc oxide films deposited by RF magnetron sputtering," Applied Surface Science, vol. 253, no. 6, pp. 3345-3348, 2007.

[11] C.-C. Kuo, C.-C. Liu, Y.-F. Jeng, C.-C. Lin, Y.-Y. Liou, and J.-L. He, "Thickness dependence of optoelectrical properties of Mo-doped in 2 O 3 films deposited on polyethersulfone substrates by ion-beam-assisted evaporation," Journal of Nanomaterials, vol. 2010, Article ID 840316, 7 pages, 2010.

[12] S. K. Park, J. I. Han, W. K. Kim, and M. G. Kwak, "Deposition of indium-tin-oxide films on polymer substrates for application in plastic-based flat panel displays," Thin Solid Films, vol. 397 , no. 1-2, pp. 49-55, 2001.

[13] E. Fortunato, A. Goncalves, V. Assuncao et al., "Growth of $\mathrm{ZnO}: \mathrm{Ga}$ thin films at room temperature on polymeric sub- strates: thickness dependence," Thin Solid Films, vol. 442, 121, 2003.

[14] T. Suzuki and T. Yamazaki, "Resistivity anomalies in tin oxide thin films," Journal of Materials Science Letters, vol. 6, no. 9, pp. 1086-1088, 1987.

[15] H. Morikawa and M. Fujita, "Crystallization and decrease in resistivity on heat treatment of amorphous indium tin oxide thin films prepared by d.c. magnetron sputtering," Thin Solid Films, vol. 339, no. 1-2, pp. 309-313, 1999.

[16] S. S. Lin, J. L. Huang, and D. F. Lii, "The effect of thickness on the properties of Ti-doped $\mathrm{ZnO}$ films by simultaneous r.f. and d.c. magnetron sputtering," Surface and Coatings Technology, vol. 190, no. 2-3, pp. 372-377, 2005.

[17] Y. Qu, T. A. Gessert, K. Ramanathan et al., "Electrical and optical properties of ion beam sputtered $\mathrm{ZnO}: \mathrm{Al}$ films as a function of film thickness," Journal of Vacuum Science \& Technology A, vol. 11, no. 4, pp. 996-1000, 1993.

[18] C. Nunes de Carvalho, A. Luis, G. Lavareda, E. Fortunato, and A. Amaral, "Effect of thickness on the properties of ITO thin films deposited by RF-PERTE on unheated, flexible, transparent substrates," Surface and Coatings Technology, vol. 151-152, pp. 252-256, 2002.

[19] H. Kim, J. S. Horwitz, G. Kushto et al., "Effect of film thickness on the properties of indium tin oxide thin films," Journal of Applied Physics, vol. 88, no. 10, pp. 6021-6025, 2000.

[20] I. Hamberg, C. G. Granqvist, K. F. Berggren, B. E. Sernelius, and L. Engström, "Bandgap widening in heavily doped oxide semiconductors used as transparent heat-reflectors," Solar Energy Materials, vol. 12, no. 6, pp. 479-490, 1985.

[21] K. L. Chopra, S. Major, and D. K. Pandya, "Transparent conductors-A status review," Thin Solid Films, vol. 102, no. 1, pp. $1-46,1983$. 

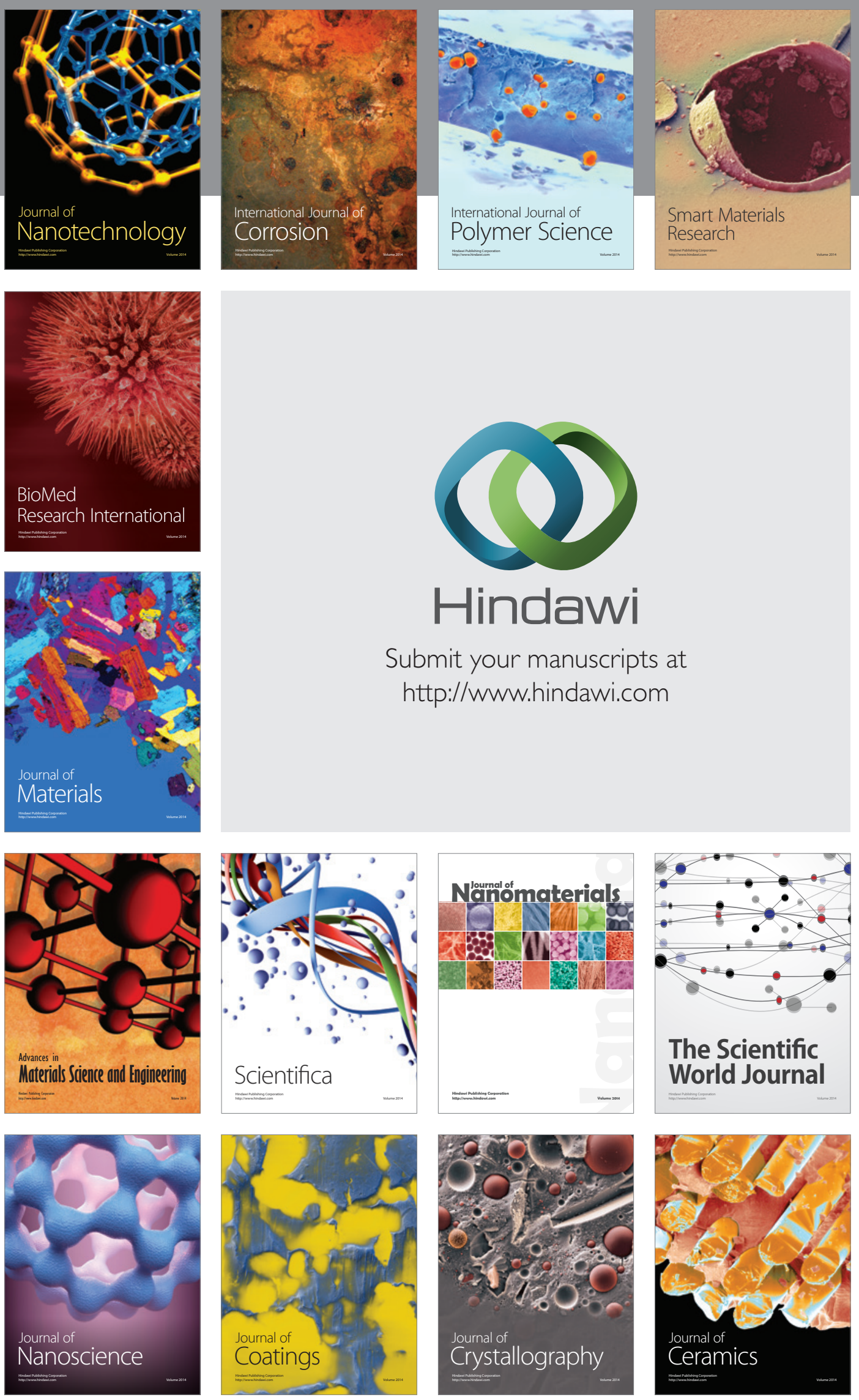

The Scientific World Journal

Submit your manuscripts at

http://www.hindawi.com

\section{World Journal}

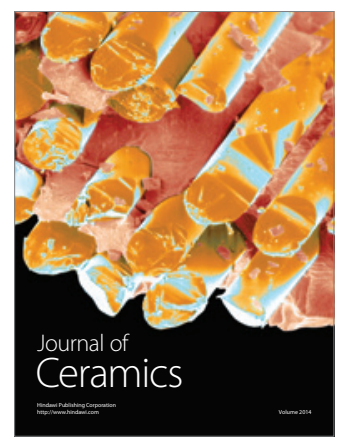

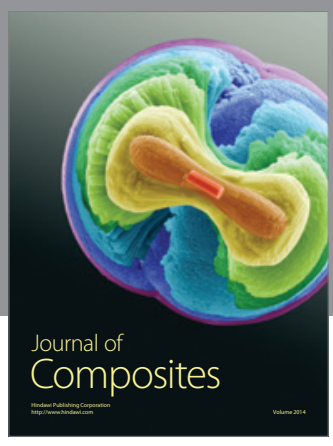
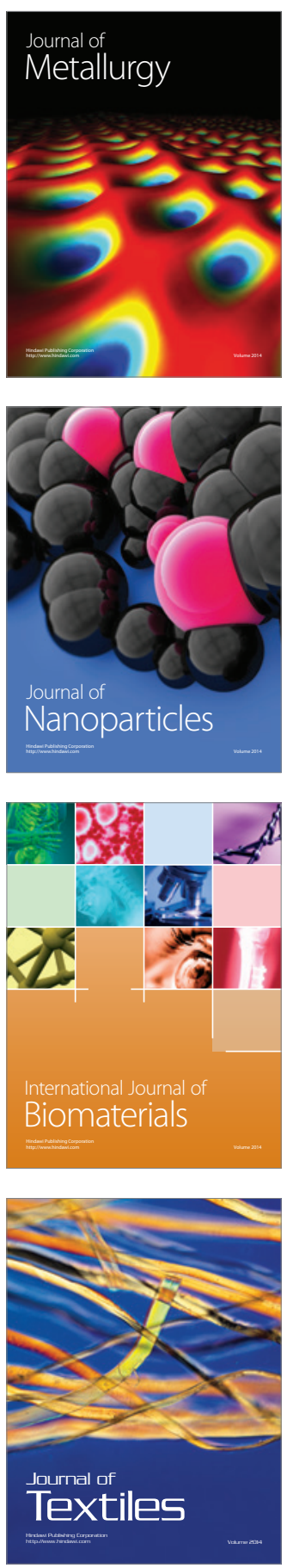